\title{
IDENTIFICAÇÃO DA MICROBIOTA GENGIVAL DE CÃES APARENTEMENTE HÍGIDOS
}

\author{
FRIAS, Danila Fernanda Rodrigues ${ }^{1}$ \\ KOZUSNY-ANDREANI, Dora Inés ${ }^{1}$ \\ PRINA, Ricardo Miranda ${ }^{2}$
}

RESUMO: A microbiota oral de animais é bastante diversificada e pouco estudada, por isso o objetivo deste trabalho foi isolar e identificar a microbiota da mucosa gengival de cães aparentemente hígidos. Foram coletadas amostras de80 cães sem raça e sexo definidos e com idade variando entre três e seis anos. A colheita do material foi realizada por meio de fricção de swab no biofilme dental do canino superior. As amostras foram transportadas ao laboratório e cultivadas em diferentes meios. Cada grupo bacteriano e de fungos isolados foram identificados pelas características morfocoloniais, morfotintoriais e bioquímico-fisiológicas convencionais. Verificou-se nas amostras avaliadas espécies bacterianas Gram positivas, dos gêneros Staphylococcus, Streptococcus, Micrococcus, Lactobacillus, Enterococcus, Propionibacterium, Bacillus e Clostridium; Gram negativas do gênero Escherichia, Pseudomonas, Proteus, Klebsiella e Neisseria, e fungos leveduriformes Candida e Malassezia. Concluiu-se que a cavidade oral de cães possui uma flora microbiana bastante diversa e que as bactérias e fungos isolados são responsáveis pela ocorrência de diversas doenças de caráter infeccioso causando sérios danos a pessoas agredidas via mordedura ou simples lambedura em feridas já existentes.

Palavras-chave: Bactérias. Fungos. Microbiota oral. Saúde pública

\section{IDENTIFICATION OF THE MICROBIOTA GINGIVAL OF APPARENTLY HEALTHY DOGS}

\begin{abstract}
SUMMARY:The oral microbiota of animals is very diverse and understudied, and therefore the purpose of this paper is to isolate and identify the microbiota of the gingival mucosa of apparently healthy dogs. Samples were collected from 80 dogs with no defined race or gender and ages between 3 and 6 years. The collection of the material was carried out by swabbing the dental plaque of the maxillary canine. Samples were transported to the laboratory and cultured in different media. Each isolated bacterial or fungal group was identified by conventional morphocolonial, morphotintorial and biochemical-physiological characteristics. The assessed samples included Gram-positive bacteria of the Staphylococcus, Streptococcus, Micrococcus, Lactobacillus, Enterococcus, Propionibacterium, Bacillus and Clostridium genus; Gram-negative bacteria of the Escherichia, Pseudomonas, Proteus, Klebsiella and Neisseria genus, and the yeast fungi Candida and Malassezia. In conclusion, the oral cavity of dogs has a very diverse microbial flora, and isolated fungi are responsible for the occurrence of many infectious diseases that cause serious harm to people bitten by dog or licked in existing wounds.
\end{abstract}

Keywords: Bacteria. Dogs. Fungi. Oral microbiota. Public heath

\section{INTRODUÇÃO}

Nos últimos anos a saúde bucal vem sendo vista com maior atenção, em virtude da Odontologia Veterinária, e com uma maior exigência por parte de proprietários, em virtude de que está diretamente ligada com a saúde geral do animal (DORN, 1998). Além disso, o conhecimento da microbiota oral de

\footnotetext{
${ }^{1}$ Universidade Brasil

${ }^{2}$ Unesp
} 
cães permite também estabelecer os prováveis patógenos envolvidos nas infecções causadas por mordeduras, tanto em animais quanto em seres humanos (CARNEIRO et al., 2001).

A microbiota oral normal de animais é bastante diversificada e complexa, sendo composta por várias bactérias e fungos sapróbios, dentre elas, podemos citar Staphylococcus aureus, Staphylococcus mitis, Streptococcus oralis, Streptococcus mutans (HIRSH; ZEE, 2003; BRAGA et al., 2005; QUINN et al., 2005, TORTORA et al., 2012). Estes patógenos podem viver harmonicamente na mucosa oral dos animais, como também podem causar lesões como úlceras, gengivites, formação de placas e cálculos dentários e periodontite (DIDRY et al., 1998).

A saúde bucal vem obtendo crescente importância na clínica de pequenos animais, pois se sabe que $80 \%$ dos cães e gatos sofrem de distúrbios na cavidade oral (HIRSH; ZEE, 2003; BRAGA et al., 2005; QUINN et al., 2005, TORTORA et al., 2012). O conhecimento da microbiota oral de cães é muito importante, pois permite orientar na escolha do melhor tratamento em caso de mordeduras e de problemas bucais (CARNEIRO et al., 2001).

A dificuldade de tratamento das infecções em ferimentos causados por mordidas de animais em seres humanos, assim como, a dificuldade em se tratar lesões na boca de cães, já foi relatada a algum tempo por Forsblom et al. (1997) e Goldstein (1998), principalmente devido à falta de conhecimento sobre a composição exata da microbiota da cavidade oral canina, ainda não descrita. Por este motivo, o presente trabalho teve como objetivo identificar a microbiota gengival de cães aparentemente hígidos na cidade de Fernandópolis, São Paulo, Brasil.

\section{MATERIAL E MÉTODO}

O projeto de pesquisa que deu origem a esse estudo foi aprovado pela Comissão de Ética para Uso de Animais - CEUA/Unicastelo, sob protocolo $n^{\circ} 1-00003 / 2012$.

A presente pesquisa foi desenvolvida no laboratório de Microbiologia da Universidade Brasil, Campus de Fernandópolis, São Paulo, Brasil. Foram coletadas amostras de 80 cães sem raça e sexo definidos e com idade variando entre três e seis anos, atendidos no Centro de Controle de Zoonoses do Município de Fernandópolis e no Hospital Veterinário da Universidade Brasil/Campus de Fernandópolis.

A avaliação clínica do periodonto e colheita das amostras foram realizadas após administração de Acepromazina $(0,05 \mathrm{mg} / \mathrm{kg})$ associado a Citrato de fentanila $(0,005 \mathrm{mg} / \mathrm{kg})$, por via intramuscular.

Os animais foram posicionados em decúbito lateral esquerdo e após o exame bucal, foram colhidas amostras da mucosa gengival por meio da fricção de um swab no biofilme dental do canino superior (esquerdo ou direito aleatoriamente). Após a colheita, o animal foi mantido em observação até total recuperação anestésica.

As amostras colhidas foram transportadas em tubos de ensaio estéreis e vedados, ao laboratório e em seguida inoculados nos meios de cultura TSA (Trypticase Soy Agar) suplementado com extrato de levedura $(5 \mathrm{mg} / \mathrm{mL}$ ) e acrescido de sangue equino desfibrinado (5\%) (TSAS); TSBV (Trypticase Soy Serum Bacitracin/Vancimicin), BBE (Ágar Bacteroides Bile Esculina); Ágar MacConkey; Ágar EMB (Eosin Methylene Blue Agar) e Agar Sabouraud acrescido de $100 \mu \mathrm{g} / \mathrm{mL}$ de cloranfenicol (WINN et al., 2008).

Os meios para isolamento de bactérias anaeróbias estritas (TSAS, TSBV, BBE) foram incubados a $37^{\circ} \mathrm{C}$, em câmara anaeróbica, realizando-se a leitura a partir de 48 horas. O TSAS foi mantido incubado em anaerobiose por até 14 dias, com realização de observação diária, para o isolamento de bactérias produtoras de pigmento negro. 
Os meios para isolamento de bactérias aeróbias, incluindo anaeróbios facultativos e microaerófilos (TSA, MacConkey, EMB) foram incubados em aerobiose, a $37^{\circ} \mathrm{C}$, em estufa bacteriológica BOD, por um período de 48 horas. O meio Ágar Sabouraud foi mantido em temperatura ambiente, e as leituras foram realizadas diariamente a partir do quinto dia, por até 21 dias. Após o período de incubação, houve a obtenção de culturas puras e a identificação preliminar, segundo características morfocoloniais, morfotintoriais e teste respiratório (SUMMANEM et al., 1993). Cada grupo bacteriano e de fungos leveduriformes também foram identificados pelas características bioquímico-fisiológicas convencionais (WINN et al., 2008).

Os dados obtidos foram tabulados e submetidos à análise da variância e a comparação das médias pelo teste de Duncan a 5\% de probabilidade.

\section{RESULTADO E DISCUSSÃO}

Em todas as amostras coletadas, notou-se a presença de bactérias Gram-positivas, Gram-negativas e fungos leveduriformes, totalizando 817 isolados (Figura 1). Destes, as espécies bacterianas estavam representadas em número significativamente maior que fungos leveduriformes, $n=605 / 74,1 \%$ e $n=212$ $/ 25,9 \%$, respectivamente.

Figura 1: Número de isolamentos de bactérias Gram positivas, Gram negativas e fungos leveduriformes da mucosa gengival de cães da Cidade de Fernandópolis, SP.

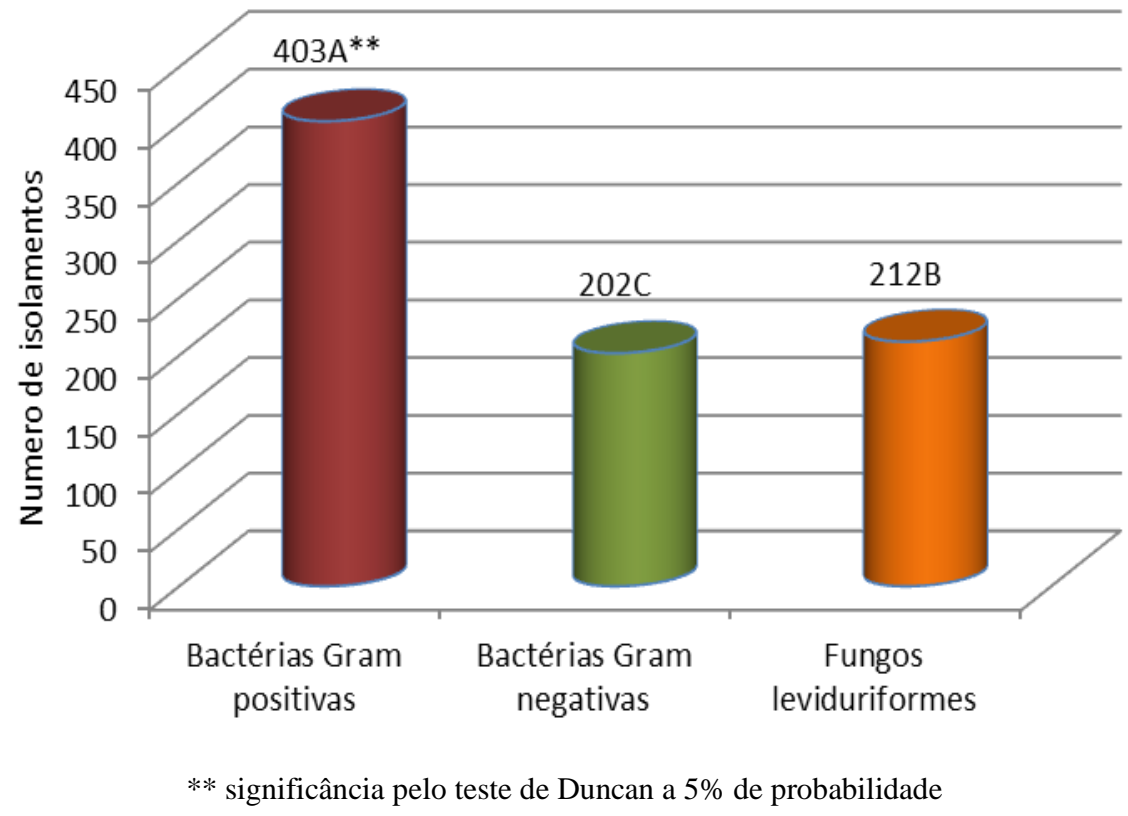

Dentre os isolados, notou-se maior frequência de bactérias Gram-positivas. Dos 605 isolados bacterianos, $403(66,6 \%)$ corresponderam a bactérias Gram positivas e 202 (33,4\%) bactérias Gramnegativas (Tabela 1). 
Tabela 1: Micro-organismos isolados da mucosa gengival de cães do Município de Fernandópolis-SP.

\begin{tabular}{|c|c|c|}
\hline & Número de animais & $\%$ \\
\hline Staphylococcus aureus & 80 & 100,0 \\
\hline Staphylococcus intermedius & 40 & 50,0 \\
\hline Staphylococcus epidermidis & 20 & 25,0 \\
\hline Streptococcus mitis & 10 & 12,5 \\
\hline Streptococcus spp. & 60 & 75,0 \\
\hline Micrococcus spp. & 45 & 56,3 \\
\hline Lactobacillus spp. & 40 & 50,0 \\
\hline Enterococcus spp. & 20 & 25,0 \\
\hline Propionibacterium spp. & 8 & 10,0 \\
\hline Bacillus subtilis & 10 & 12,5 \\
\hline Bacillus spp. & 25 & 31,3 \\
\hline Clostridium spp. & 45 & 56,3 \\
\hline Escherichia coli & 72 & 90,0 \\
\hline Pseudomonas aeruginosa & 50 & 62,5 \\
\hline Pseudomonas spp. & 25 & 31,3 \\
\hline Proteus mirabilis & 12 & 15,0 \\
\hline Proteus vulgaris & 15 & 18,8 \\
\hline Klebsiella spp. & 22 & 27,5 \\
\hline Neisseria spp. & 6 & 7,5 \\
\hline Candida albicans & 78 & 97,5 \\
\hline Candida spp. & 50 & 62,5 \\
\hline Malassezia pachydermatis & 28 & 35,0 \\
\hline Malassezia spp. & 56 & 70,0 \\
\hline Valor de $p$ & $<0.001$ & \\
\hline CV\% & 2.11 & \\
\hline
\end{tabular}

Significativo ao nível de $1 \%$ de probabilidade (p <0.01), pelo teste de Duncan.

Entre as espécies bacterianas Gram positivas foram isolados os gêneros Staphylococcus, Streptococcus, Micrococcus, Lactobacillus, Enterococcus, Propionibacterium, Bacillus e Clostridium, e nas Gram negativas Escherichia, Pseudomonas, Proteus, Klebsiella e Neisseria. Shafir; Carter (1976) avaliando 50 cães isolou da cavidade oral E.coli, S. aureus, S. epidermidis, Neisseria, Micrococcus e Bacillus spp., entre outros. Os gêneros Neisseria, Staphylococcus, Streptococcus e Clostridium foram identificados também por Elliot et al.(2005), Dewhirst et al.(2012) e Stourgeon et al. (2012).

As espécies bacterianas isoladas com maior frequência foram Staphylococcus aureus, Streptocococcus spp. e Escherichia coli. Já, as espécies de fungos leveduriformes foram Candida albicans e Malassezia spp. Alguns autores já concluíram que a maior parte das bactérias isoladas da cavidade oral de animais aparentemente hígidos são gram-positivas (DORN, 1998; GREENE, 2006). Com relação à 
espécie e gênero de bactérias, também citaram Streptococcus spp., Staphylococcus spp. e a enterobactéria Escherichia coli como as mais prevalentes (DORN, 1998; HIRSH; ZEE, 2003).

A presença de fungos leveduriformes dos gêneros Candida e Malassezia nas amostras também foi detectada, embora não tenham sido observadas diferenças estatísticas entre os gêneros. Estes resultados são semelhantes aos obtidos por Britto et al. (2009) e Santin et al. (2013) que isolaram da mucosa oral de cães ambos os fungos. Estes autores afirmam que M. pachydermatis e Candida spp. fazem parte da microbiota normal de diferentes regiões da cavidade oral cães, sendo isolados em maior proporção de animais acometidos por halitose, sugerindo que estes fungos cumprem um papel importante no comprometimento da saúde oral destes animais. Ainda, segundo Santin et al. (2013), as leveduras colonizam preferencialmente áreas com maior umidade como as mucosas.

A ocorrência de $C$. albicans na cavidade oral mostra a probabilidade desta espécie estar presente em diferentes proporções na microbiota normal de seres humanos e animais (HAYASHI et al., 2008). E autores já demonstraram a ocorrência de estomatite em cães e no ser humano causada por este agente (QUINN et al., 2005; TORTORA et al., 2012).

Um fator importante a salientar é a elevada ocorrência de acidentes com mordeduras de cães envolvendo crianças devido a intensa atividade e proximidade destas com animais (FRIAS; LAGES; CARVALHO, 2011). A contaminação dos ferimentos em casos de mordeduras, devido a presença de uma grande quantidade de microrganismos na cavidade oral destes animais, pode causar sérios casos de infecções, acompanhados ou não de quadros de necrose grave, que podem deixar sequelas principalmente estéticas, ou dependendo da gravidade, levar a morte (MACEDO; CAMARGO; ALMEIDA, 2006; RUIFENG et al., 2013).

Mesmo com o isolamento e identificação de diversos agentes na cavidade oral de cães, pesquisas mostram que muitas bactérias presentes neste local ainda não são cultiváveis pelos métodos convencionais, sendo necessária a utilização de técnicas moleculares para a sua identificação (SAPHIR; CARTER, 1976; REZENDE et al., 2004; ELLIOT et al., 2005; LAVIE et al., 2009; STURGEON, 2012; YAMASKI et al., 2012). Estudos realizados por métodos moleculares, que não dependem de cultivos prévios, permitiram identificar 181 gêneros bacterianos na cavidade oral de seis cães (STURGEON, 2012). Com a metodologia utilizada, foram detectados 13 gêneros bacterianos em 50 amostras.

\section{CONCLUSÃO}

De acordo com a metodologia empregada e pelos resultados obtidos concluiu-se que a cavidade oral dos cães usados no estudo estava composta por treze gêneros bacterianos e dois gêneros de fungos leveduriformes., e que a maioria das espécies bacterianas isoladas são micro-organismos que estão envolvidos frequentemente em doenças de caráter infeccioso, que podem desencadear o desenvolvimento de infecções em feridas causadas por mordidas, tanto em seres humanos, como em outros animais. Por isso, torna-se necessário orientar os profissionais de saúde a estarem sempre atentos a possibilidade de contaminação quando da ocorrência de acidentes com mordeduras caninas ou lambeduras em uma ferida previamente existente.

\section{REFERÊNCIAS}

BRAGA, C.A.S.B.et al. Isolamento e identificação da microbiota periodontal de cães da raça Pastor Alemão. Ciência Rural, v.35, n.2, p.385-390, 2005. 
BRITO, E.H.S.et al. The anatomical distribution and antimicrobial susceptibility of yeast species isolated from healthy dogs. The Veterinary Journal, v.182, p.320-326, 2009.

CARNEIRO, L.P. et al. External skeletal fixation in dogs: clinical and microbiological evaluation. Arquivo Brasileiro de Medicina Veterinária e Zootecnia, v.53, n.4, p.437-444, 2001.

DEWHIRST, F.E. et al. The canine oral microbiome. 2012. Disponível em <http://journals.plos.org/plosone/article?id=10.1371/journal.pone.0036067>. Acesso: 13 jan. 2018.

DIDRY, N. et al. Antimicrobial activity of aerial parts of Droserapeltata Smith on oral bacteria. Journal of Ethnopharmacology, v.60, p.91-96, 1998.

DORN, A. S. Introdução para a odontologia veterinária. In: SLATTER, D. Manual de cirurgia de pequenos animais. 2.ed.. São Paulo: Manole, 1998.

ELLIOT, D.R. et al. Cultivable oral microbiota of domestics dogs. Journal of Clinical Microbiology, v.43, n.11, p.5470-5476, 2005.

FORSBLOM, B. et al. Characterization of anaerobic, Gram negative, non pigmented, saccharolytic rods from sub gengival sites in dog. Clinical Infectious Diseases, v.25, n.2, p.100-106, 1997.

FRIAS, D. F. R.; LAGES, S. L. S.; CARVALHO, A. A. B. Avaliação da conduta de profilaxia antirrábica humana indicada para pessoas envolvidas $m$ agravos com cães e gatos no Município de Jaboticabal, SP, no período de 2000 a 2006. Revista Brasileira de Epidemiologia, v.14, n.4, p. 722-732, 2011.

GOLDSTEIN, E.J.C. New horizons in the bacteriology, antimicrobial susceptibility and therapy of animal bite wounds. Journal of Medical Microbiology, v.47, p.95-97, 1998.

GREENE, C.E. Infectious diseases of the dog and cat. 3.ed. St. Louis: Saunders, 1387p, 2006.

HAYASHI, K.; TAKADA, K.; HIRASAWA, M. Yeast-form fungi from dog oral cavity. IADR 86th General Session; Exhibition. Microbiology/Immunology and Infection Control Program, 2008. Disponível em < http://iadr.confex.com/iadr/2008Toronto/techprogram/abstract_105472.htm>. Acesso: 17 jan. 2018.

HIRSH, D.C.; ZEE, Y.C. Microbiologia Veterinária. Rio de Janeiro: Guanabara Koogan, 446p, 2003.

LAVIE, E. et al. Comparison and the distribution of oral cavity bacteria in various dog populations. Israel Journal of Veterinary Medicine, v.64, n.3, p.78, 2009.

MACEDO, J. L. S.; CAMARGO, L. M.; ALMEIDA, P. F. Estudo prospectivo do fechamento primário das mordeduras caninas e humanas na face e no couro cabeludo. Revista da Sociedade Brasileira de Cirurgia Plástica, v.21, n.1, p.23-29, 2006.

QUINN, P.J. et al. Microbiologia veterinária e doenças infecciosas. Porto Alegre: Artmed, p.115-130, 2005.

REZENDE, R. J. et al. Frequência de placa bacteriana dental em cães. Bioscience Journal, v.20, n.2, p.113-118, 2004.

RUI-FENG, C. et al. Emergency treatment on facial laceration of dog bite wounds with immediate primary closure: a prospective randomized trial study. BMC Emergency Medicine, v.13, s:1, p.1-5, 2013.

SANTINI, R. et al. Clinical and mycological analysis of dog's oral cavity. Brazilian Journal of Microbiology, v.44, n.1, p.139-143, 2013. 
SAPHIR, D.A.; CARTER, G.R. Gengival flora of the dog with special reference to bacteria associated with bites. Journal of Clinical Microbiology, v.3, n.3, p.344-349, 1976.

STURGEON, A.et al. Metagenomic analysis of the canine oral vaity as revealed by high-throughput pyrosequencing of the 16S rRNA gene.Veterinary Microbiology, v.11, p.1, 2012.

SUMMANEM, P.; BARON, E.J.; CITRON, D.M. Wadsworth Anaerobic Bacteriology Manual. Belmont: Star Publishing, 1993.

TORTORA, G.J.; FUNKE, B.R.; CASE, C.L. Microbiologia. Porto Alegre: Artmed, 934p, 2012.

WINN, W.et al.Diagnóstico microbiológico: texto e atlas colorido. 6.ed. Rio de Janeiro: Guanabara Koogan, 1760 p, 2008.

YAMASKI, Y.et al. Distribution of periodontopathic bacterial species in dogs and theirs owners. Archives of Oral Biology, v.57, p.1183-1188, 2012. 
